\title{
How Meaningful are Statements about the Desired Number of Additional Children? An Analysis of 1968 Pakistani Data
}

\author{
M. ALI KHAN and I. SIRAGELDIN*
}

In this paper we present a methodology for studying the desired number of additional children. Our methodology involves a generalization of our earlier work and an application of the estimator proposed by Heckman and the two-stage simultaneous Tobit estimator proposed by Nelson and Olson.

Recent analyses of desired additional fertility have limited themselves to a dependent variable which is dichotomous, taking the value of one if the respondent wants additional children and of zero otherwise. ${ }^{1}$ However, these studies ignore the information which is typically available. It is usual in most KAP surveys ${ }^{2}$ to follow up a respondent's response indicating his/her willingness to have additional children by a further question as to their desired number. Any estimates based on reducing these responses to a single number are obviously inefficient. It is the object of this paper to provide estimates, based on 1968 Pakistani data, which are free from these difficulties.

Such corrected estimates are of more than a purely technical importance. The desire to have additional children, $A C$, has been used to study at least three substantive issues and our estimates have obvious implications for each of them. Firstly, Namboodiri [25] and, following him, others ${ }^{3}$ have argued that the effect of socioeconomic variables on fertility can be more effectively gauged by studying $A C$ rather

*Dr. Khan and Dr. Sirageldin are Professors at the Johns Hopkins University, Baltimore (Md., USA), the former in the Department of Political Economy, and the latter in the Departments of Political Economy and Population Dynamics. They are deeply indebted to Susan Cochrane for a careful reading of the manuscript and for her constructive comments. They also thank Lou Maccini, N.K. Namboodiri, Rob Seidman and Julian Simon for encouragement and helpful discussions. Their final acknowledgement is to Dave Binko for computational assistance. The research reported in this paper was supported in part by a World Bank Grant. The views expressed here, as well as any errors, are solely of the authors.

${ }^{1}$ See, for example, Namboodiri [24; 26], Rosenzweig and Seiver [29], McFadden [22], and Khan and Sirageldin $[13 ; 14]$. All these papers attempt to go beyond descriptive classification tables. If we include papers with such descriptive analyses, the literature is voluminous.

${ }^{2}$ As is well known, KAP stand for knowledge, attitudes and practice.

${ }^{3}$ See references in Footnote 1. 
than completed family size. Secondly, McFadden [22] and Khan and Sirageldin [14] have used $A C$ to quantify son-preference. ${ }^{4}$ Thirdly, Khan and Sirageldin [13] have used $A C$ to study intrafamily interaction. The fact that all of these issues are interrelated hardly needs emphasis.

Our analysis and results also have a bearing on two further questions. They shed light on how credible numerical responses are to questions concerning the desired additional fertility. Further, they can be seen as an investigation of the determinants of these responses, and such an investigation is important since measures of desired additional fertility are being increasingly investigated as predictors of actual subsequent fertility. ${ }^{5}$

The paper is divided into five sections. Sections 1 and 2 elaborate our methodology. The first is devoted to a discussion of the theoretical model while the second describes the estimating methods. Sections 3 and 4 present the empirical results. The last section summarizes our salient findings relating to husband-wife interaction and son-preference.

\section{THE THEORETICAL MODEL}

The model is based on Khan and Sirageldin [13] but here we considerably sharpen and extend the ideas presented there. The basic idea is suggested by the partial adjustment model which is extensively used, for example, in empirical studies of the firm's behaviour. In our context, the model suggests the hypothesis that a particular respondent's desired change in the number of the existing stock of children depends on (i) the discrepancy between the ideal and actual numbers of (a) boys and (b) girls and (ii) the spouse's desired change in the number of the existing stock of children. More formally, we have

$$
\begin{aligned}
& N A C_{W}^{*}=\lambda_{W B}\left(B-B_{W}^{*}\right)+\lambda_{W G}\left(G-G_{W}^{*}\right)+\mu_{W} N A C_{H}^{*} \quad \cdots \\
& N A C_{H}^{*}=\lambda_{H B}\left(B-B_{H}^{*}\right)+\lambda_{H G}\left(G-G_{H}^{*}\right)+\mu_{H} N A C_{W}^{*} \quad \cdots
\end{aligned}
$$

where $N A C_{i}^{*}$ denotes the desired change and $B_{i}^{*}$ and $G_{i}^{*}$ the desired number of boys and girls respectively, all these variables pertaining to the $i$ th respondent who may be the wife $(W)$ or the husband $(H) . B$ and $G$ are the numbers of living boys and girls. Two points need to be emphasized in the specification (1.1). The first is that all the variables need to be qualified by a subscript $t$ signifying the time of interview. The second is that $N A C_{i}^{*}$ can be positive or negative, i.e. the phrase "desired change in the

${ }^{4}$ The son-preference issue has been much discussed, especially in the last five years; see Khan and Sirageldin [13], for detailed references.

${ }^{5}$ See Blake [4], Coombs [6], Bumpass [5], Kruegel [15], Freedman et al. [7], Westoff and Ryder [35], and Hermalin et al. [10], among others. existing stock of children" is purposely chosen. But, of course, $N A C_{i}^{*}$ is an unobservable or, to put it more fashionably, a latent variable. For one thing, the interviewers do not ask the respondents whether they want to diminish their existing stock of children and, for another, such an answer would not be forthcoming even if the situation warranted it. ${ }^{6}$ However, if desires are to be meaningful regulators of fertility behaviour, they must be as relevant to the situations involving excesses as they are to those involving deficits. The assumption that thry do have such a relevance represents the essential novelty of our approach.

However, we have yet to face the question as to what observable variables underlie the unobservable $N A C^{*}{ }_{i}$. The answer to this is clear. These are the variables $N A C_{i}$ denoting the desired number of additional children.

We thus have

$$
\begin{aligned}
& N A C_{i}^{*}=N A C_{i} \quad \text { if } N A C_{i}^{*}>0 \quad(\mathrm{i}=W, H) ; \\
& =0 \quad \text { if } N A C_{i}^{*} \leq 0
\end{aligned}
$$

The specification of our basic hypothesis is now complete. However, it merits further explanation in terms of an alternative specification which we do not propose. This is given by

$$
\left.\begin{array}{rl}
N A C_{W} & =\lambda_{W B}\left(B-B_{W}^{*}\right)+\lambda_{W G}\left(G-G_{W}^{*}\right)+\mu_{W} N A C_{H} \text { if } R H S>0 ; \\
& =0 \text { otherwise } \\
N A C_{H} & =\lambda_{H B}\left(B-B_{H}^{*}\right)+\lambda_{H G}\left(G-G_{H}^{*}\right)+\mu_{H} N A C_{W} \text { if } R H S>0 ; \\
& =0 \text { otherwise }
\end{array}\right\}
$$

As we shall see subsequently, the specification (1.2) gives rise to estimation problems of a kind different from those of (1.1). What should be noted here is the conceptual difference between specifications (1.1) and (1.2). In (1.2) a respondent's desired

${ }^{6}$ This is not to say that it is impossible to construct measures which measure decreased desired fertility. If "stocks" were taken to indicate some value units and not merely physical units, say, a weighted average of both quality and quantity of children, then the idea of varying the stock of child services in both directions becomes conceptually and socially feasible. Simply, parents would adjust their inputs in the production of children in order to increase or decrease the total "value" of their current stock. Such conceptual and possible empirical extension is left for future investigation. For purposes of this study, it is assumed that the option of adjusting child quality is not a feasible decision parameter for parents in the Pakistani social context. In any case, the data limitations bar such an extension. 
from our sample all those observations for which $N A C_{i}=0$. The former procedure would lead to biased estimates and the latter procedure suffers from the 'censored sample' problem, ${ }^{9}$ well known especially to labour economists. Simply put, the essence of this problem is that determinants of the number of additional children are precisely those that govern the respondent's desire to reduce or keep unchanged the existing stock of children, and, by excluding such respondents, we are throwing away information. Thus the method of ordinary least squares is not suitable and we have to apply Tobit estimators. These will be described presently but at this point we have to face up to the problem we laid aside at the beginning of this discussion, namely, the problem of simultaneity. It is in an attempt to overcome both of these difficulties that we shall be relying on two estimating methods. The first is the twostage estimator due to Heckman [8;9] and further studied by Lee [16] and Lee et al. [17]. ${ }^{10}$ The second is the two-stage Tobit estimator proposed by Nelson and Olson [27] and further studied by amemiya [1]. For the sake of comparison, we shall also be presenting two-stage least-squares estimates ${ }^{11}$ of the parameters of our model.

The idea of Heckman's estimator can be simply described. It is an attempt to allow for the selectivity bias that is introduced if we run ordinary least squares on the subsample for which the dependent variable is positive. In terms of our earlier discussion, it introduces additional explanatory variables to eliminate the censored sample problem. The generation of these explanatory variables constitutes the first stage in Heckman's estimator. What one is after is the probability of a dependent variable taking the value of zero. This can be estimated through probit analysis. Since probit analysis has already been used in our earlier work [14], we can afford to be brief here. For both husband and wife, the dependent variables $N A C_{i}$ are reduced into dichotomous variables $A C_{i}$ which take the value of 1 if the respondent wants additional children and of zero otherwise. $A C_{i}$ is then regressed on all of the exogenous variables. Let the normalized probit estimates of the coefficients of their parameters be denoted by the vectors $b_{H}$ and $b_{W}$. We then calculate for all positive observations $j$, and for each spouse, the inverse of the Mills ratio, i.e. the variables

$$
m_{j i}=\frac{f\left(X_{i j} b_{i}\right)}{1-F\left(X_{i j} b_{i}\right)} \quad i=W, H
$$

${ }^{9}$ See Maddala $[20 ; 21]$ for expository surveys.

10 It is worth drawing the reader's attention to the fact that the model in Lee et al. [16] is not general enough to cover our specification (1.4). The problem lies in that the switching of regimes is based on a single valued criterion. Nevertheless we give this reference because it is the only comprehensive attempt to calculate the variance-covariance matrix of the Heckman estimators in a multivariate context.

${ }^{11}$ See, for example, Maddala [19]. where $f$ and $F$, respectively, are the density and distribution functions of the standard normal distribution, and $X_{i j}$ represents the values of the exogenous variabes for the $j$ th observation.

Once we obtain the $m_{j i}$, we are ready for the second stage. This consists in excluding all observations for which either of our dependent variables has a zero value. The two-stage least squares are run on this subsample with $m_{W}$ and $m_{H}$ as additional explanatory variables occurring in both equations. This yields consistent estimates for all the structural equation parameters of the model. However, the standard errors of all these estimates are biased and, hence, no confidence can be placed in tests of significance. ${ }^{12}$ For these, what is called for is a full information method ${ }^{13}$ to be used in the second stage. This was beyond our computational ability and, hence, was not pursued. At any rate, the two-stage Tobit estimator of Nelson and Olson [27] is tailor-made for our model,

The references for Tobit estimators are Tobin [34] and Amemiya [3]. The latter gives a comprehensive treatment and there is no point in repetition here. The reader is particularly referred to the likelihood function given as equations (3.1) and (3.2) in Amemiya's paper. This is maximized with respect to the parameters to obtain the maximum likelihood normal equations. The Tobit estimators are the roots of these equations, and they are calculated by an iterative Newton-Rapheson procedure with 0.00001 as the tolerance level. As Amemiya has shown, these estimates are strongly consistent and asymptotically normal with their variancecovariance matrix equal to the matrix of second derivatives of the logarithm of the likelihood function evaluated at the point of maximum likelihood. Using this matrix, t-tests can be used to test simple regressor hypotheses. It should also be noted that due to the non-linear nature of the model, the effect of a unit change in an explanatory variable on the dependent variable depends on the particular value of the vector of the explanatory variables. In the sequel we shall be reporting such changes evaluated at the average values of the explanatory variables.

Once we understand the Tobit estimator, the logic of the two-stage Tobit estimator of Nelson and Olson [27] is straightforward. Before describing this, it is well to state that such an estimator has been further studied by Amemiy $\mathrm{a}^{14}[1]$ and comes within the general class of two-stage analogues [20]. The idea is identical to that underlying the conventional two-stage least-squares estimator. The identification criteria are precisely the same. The first stage is to get the reduced form of the

\footnotetext{
${ }^{12}$ See especially Heckman [9] for more details.
${ }^{13}$ For instance, the three-stage least squares esti
} [19]. A memiya studies a two-equation model with one of the endogenous variables being

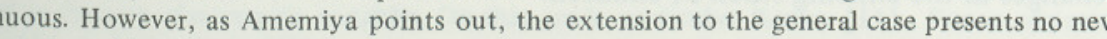
conceptual problems. 
model and estimate each equation by the Tobit method described earlier. These estimated equations are used to obtain predicted values of each of the endogenous variables. In the second stage, the structural equations are estimated again by the Tobit method but with the predicted values substituted for each of the endogenous variables when the latter are included as independent, explanatory variables.

We conclude this section with two further remarks. The first is a justification of the use of the Heckman estimator when we are already using the Nelson-Olson estimator. This lies in the fact that the Nelson-Olson estimator is not the best asymptotically normal estimator. Indeed, Amemiya [1] discusses one estimator which always performs better than the Nelson-Olson estimator for a specific model and another which cannot be ranked. Our second remark relates to an alternative simul taneous-equation generalization of the multivariate Tobit model discussed by Amemiya [2]. The estimators he proposes in his paper are relevant to the estimation of a model such as the one given in equations (1.2a) and (1.2b). Since we do not make use of this specification here, we refer the reader to Amemiya's paper for a detailed treatment.

\section{DATA SOURCES AND DEFINITIONS OF VARIABLES}

The paper is based on data collected as part of a national survey, the Impact Survey, in West Pakistan (now Pakistan) in 1968-69. For a full description of the survey, see [18], Sirageldin and Hardee [33] and Sirageldin [32]. The survey was designed to elicit information on knowledge, attitudes and practice of family plan. ning. It also obtained pregnancy histories and some details on background socioeconomic variables of a sample of ever-married women in 2,500 households. About half of the households were randomly selected for an independent interviewing of the husbands of currently married women. A total of 1,027 husbands' interview schedules were successfully matched with their wives' schedules. It is on this sub. sample of married couples that the present paper is based. A comparison of the responses of all the respondents in the survey with those of the subsample of the couples used in this study shows no systematic differences and, therefore, does not raise major concerns about the representativeness of the subsample; for more details on this, see N. Shah [31]. The sample used includes a cross-section of rural as well as urban couples and is, therefore, more comprehensive than those in most of the studies conducted on this subject anywhere, and more comprehensive than those of most of the surveys in this part of the world.

We now present the variables that are used in the subsequent analysis. We begin with a description of our dependent variables which quantify the desired changes in the existing stock of children.
$N A C_{W}\left(N A C_{H}\right): \quad$ The number of additional children by the wife (husband). This information was elicited from all respondents who answered affirmatively the question "Do you want any (more) children?"

It is worth emphasizing that the variables $N A C_{i}$ have nothing to say about spacing of these desired additional children. The $N A C_{i}$ pertain to the period from the time of interview to the end of the reproductive life cycle. It is because of this that the $\lambda \mathrm{s}$ in (1.1) and in (1.4) pertain to a once-and-for-all adjustment.

In keeping with our discussion in Section 1, we attempt to explain the variation in the dependent variables $N A C_{i}$ by a variety of economic, demographic and sociological variables. ${ }^{15}$ We present each in turn.

\section{Economic Variables}

$A D W(A D H)$ : Dummy variable which takes the value of 1 if the wife (husband) considered their income during the past 12 months adequate or more than adequate, and of zero otherwise.

\section{Demographic Variables}

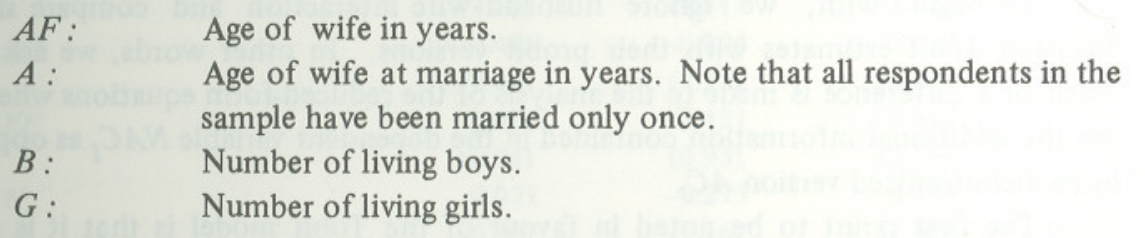

A : $\quad$ Age of wife at marriage in years. Note that all respondents in the sample have been married only once.

$B$ : $\quad$ Number of living boys.

$G$ : $\quad$ Number of living girls.

The next two variables can be better described if we mention the corresponding questions that were asked. The first question was, "What is the appropriate number of children for a family like yours?" For those who gave a numerical value, the follow-up question was, "How many of these would be boys and how many girls?" The answer to this question gave us a measure of the number of boys and girls considered ideal. Hence, we have

$$
\begin{aligned}
B_{W}^{*}\left(B_{H}^{*}\right): & \text { Number of boys considered ideal by the wife (husband). } \\
G_{W}^{*}\left(G_{H}^{*}\right): & \text { Number of girls considered ideal by the wife (husband). } \\
D B W(D B H): & B_{W}^{*}-B\left(B_{H}^{*}-B\right) \\
D G W(D G H): & G_{W}^{*}-G\left(G_{H}^{*}-G\right)
\end{aligned}
$$

${ }^{15}$ These labels are for classificatory purposes only. One of the insights of the ChicagoColumbia approach is precisely that sociological variables such as education of the wife can be viewed as proxies of economic variables. On this, see in particular Keeley [11]. For an opposing viewpoint, see Leibenstein [18]. 


\section{Sociological Variables}

$E M$ : $\quad$ Education of husband in years.

$E F$ :

Dummy variable which takes the value of 1 if the wife is "literate" and of zero otherwise.

$U$ : $\quad$ Dummy variable which takes the value of 1 if the respondent lives in an urban area and of zero otherwise.

$N$ : $\quad$ Dummy variable which takes the value of 1 if the respondent has a nuclear family and of zero otherwise.

Almost all of the analyses reported below are carried out on a subsample of women who married only once, were currently married and were under 40 years of age. The age restriction is imposed to give greater prominence to behavioural, rather than biological, variables. We also excluded, in addition, couples, either of whose members could not give a yes-or-no answer to the question underlying the variables $N A C_{i}$ or a numerical response to the question underlying $D B_{i}$ and $D G_{i}$. This reduces our subsample to 804 .

\section{THE RESULTS}

To begin with, we ignore husband-wife interaction and compare singleequation Tobit estimates with their probit versions. In other words, we ask how much of a difference is made to the analysis of the reduced-form equations when we use the additional information contained in the dependent variable $N A C_{i}$ as opposed to its dichotomized version $A C_{i}$

The first point to be noted in favour of the Tobit model is that it is more useful for studying the effect of marginal changes in the explanatory variables. With $A C_{i}$ for a marginal change in a particular explanatory variable, all we can calculate is the corresponding change in the probability of $A C_{i}$ taking a given value, typically zero or one. Such a statistic is difficult to interpret, especially for policy makers. With $N A C_{i}$ for a marginal change in any explanatory variable, we can obtain the corresponding change in the expected number of children desired by the respondent.

However, what is a more interesting question is whether the use of $N A C_{i}$ causes qualitative changes in any of our previous findings. Table 1 reproduces probit estimates from Khan and Sirageldin [13] and compares them with the Tobit estimates. It is clear that there are no real surprises here. Begin with wives' equations. Except for husband's education, $E M$, and wife's age at marriage, $A$, all variables increase in significance. The $A$ continues to be significant in the Tobit run but this is not so for $E M$. For the husbands' equations, urbanization, $U$, is significant in the Tobit run and with the expected sign and the coefficients of the relative income variables. The $A D H$ and $A D W$ further decrease in significance. The husbands' equations also bring out our earlier point regarding the superiority of the Tobit model for calculating the effects of marginal changes in the explanatory variables. Education of
Table 1

A Comparison of Probit and Tobit Estimates of the Reduced Form Equations 1

\begin{tabular}{|c|c|c|c|c|}
\hline \multirow[b]{2}{*}{ Independent Variables } & \multicolumn{2}{|c|}{ Wives' Equation $^{2}$} & \multicolumn{2}{|c|}{ Husbands' Equation ${ }^{2}$} \\
\hline & $A C_{W}$ & $N A C_{W}$ & $A C_{H}$ & $N A C_{H}$ \\
\hline (1) & (2) & (3) & (4) & $(5)$ \\
\hline Intercept & $\begin{array}{c}0.940 \\
(2.46)\end{array}$ & $\begin{array}{c}3.646 \\
(4.66)\end{array}$ & $\begin{array}{c}3.05 \\
(0.07)\end{array}$ & $\begin{array}{r}4.003 \\
(5.41)\end{array}$ \\
\hline$A D H$ & $\begin{array}{c}-0.139 \\
(1.71)\end{array}$ & $\begin{array}{c}-0.356 \\
(1.83)\end{array}$ & $\begin{array}{r}0.125 \\
(1.52)\end{array}$ & $\begin{array}{r}0.059 \\
(0.38)\end{array}$ \\
\hline$A D W$ & $\begin{array}{c}-0.164 \\
(1.56)\end{array}$ & $\begin{array}{c}-0.570 \\
(2.44)\end{array}$ & $\begin{array}{c}0.126 \\
(1.07)\end{array}$ & $\begin{array}{r}0.053 \\
(0.25)\end{array}$ \\
\hline$A F$ & $\begin{array}{c}-0.032 \\
(2.92)\end{array}$ & $\begin{array}{c}-0.088 \\
(3.68)\end{array}$ & $\begin{array}{c}-0.063 \\
(5.13)\end{array}$ & $\begin{array}{c}-0.079 \\
(3.49)\end{array}$ \\
\hline 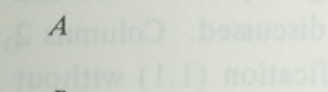 & $\begin{array}{c}0.062 \\
(2.92)\end{array}$ & $\begin{array}{c}0.112 \\
(2.61)\end{array}$ & $\begin{array}{c}0.012 \\
(0.51)\end{array}$ & $\begin{array}{r}0.036 \\
(0.90)\end{array}$ \\
\hline$B$ & $\begin{array}{c}-0.391 \\
(8.27)\end{array}$ & $\begin{array}{c}-1.000 \\
(8.96)\end{array}$ & $\begin{array}{c}-0.455 \\
(9.26)\end{array}$ & $\begin{array}{r}-0.905 \\
(8.82)\end{array}$ \\
\hline 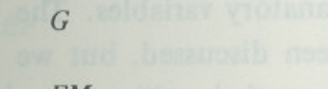 & $\begin{array}{c}-0.140 \\
(3.00)\end{array}$ & $\begin{array}{c}-0.484 \\
(4.41)\end{array}$ & $\begin{array}{c}-0.180 \\
(3.72)\end{array}$ & $\begin{array}{c}-0.452 \\
(4.47)\end{array}$ \\
\hline 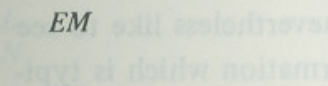 & $\begin{array}{c}-0.488 \\
(2.46)\end{array}$ & $\begin{array}{c}-0.004 \\
(1.23)\end{array}$ & $\begin{array}{c}0.017 \\
(0.07)\end{array}$ & $\begin{array}{c}-0.000 \\
(0.02)\end{array}$ \\
\hline$E F$ & $\begin{array}{l}0.070 \\
(0.34)\end{array}$ & $\begin{array}{c}-0.431 \\
(0.93)\end{array}$ & $\begin{array}{c}-0.610 \\
(2.79)\end{array}$ & $\begin{array}{c}-0.103 \\
(0.25)\end{array}$ \\
\hline 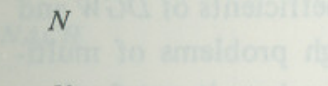 & $\begin{array}{r}0.021 \\
(0.20)\end{array}$ & $\begin{array}{c}-0.273 \\
(1.16)\end{array}$ & $\begin{array}{c}-0.118 \\
(1.02)\end{array}$ & $\begin{array}{c}-0.166 \\
(0.76)\end{array}$ \\
\hline$U$ & $\begin{array}{c}-0.138 \\
(1.25)\end{array}$ & $\begin{array}{c}-0.411 \\
(1.71)\end{array}$ & $\begin{array}{c}-0.044 \\
(0.35)\end{array}$ & $\begin{array}{c}-0.450 \\
(2.00)\end{array}$ \\
\hline$V^{3}$ & $\begin{array}{c}-0.046 \\
(1.28)\end{array}$ & - & $\begin{array}{l}40.061 \\
(1.52)\end{array}$ & - \\
\hline Log of Likelihood & -128 & -1128 & -182 & -1191 \\
\hline Last Degrees of Freedom & 11 & 10 & 11 & 10 \\
\hline Number of Observations & 804 & 804 & 804 & 804 \\
\hline Mean of Depend. Var. & 0.51 & 1.387 & 0.68 & 1.468 \\
\hline Number of Limit Obs. & - & 427 & - & 393 \\
\hline Standard Error of Reg. & - & 2.641 & - & 2.531 \\
\hline
\end{tabular}

${ }_{2}^{1}$ Figures in brackets denote $\mathrm{t}$-statistics.

${ }^{2} A C_{i}$ are dichotomous variables and $N A C_{i}$ are truncated variables. Accordingly the estimators are respectively Probit and Tobit.

${ }^{3} V$ is a dichotomous variable which takes the value of 1 if the wife observes purdah (i.e. veils herself) and of zero otherwise. 
the wife, $E F$, is significant at more than 1-percent level in both models, but it is the Tobit estimate that brings out clearly its irrelevance for policy. Every thing else being constant, a change in the status of a wife from being illiterate to literate (a change in the value of $E F$ from zero to unity) causes a negligible but statistically significant change in the expected, desired number of children. But, of course, these are re duced-form estimates and we shall see in the sequel the extent to which they differ from structural estimates.

The estimates presented in Table 1 also give support to the point of view that statements about the desired number of additional children contain valuable informa tion deserving of further analysis. Given the quantative similarity between the probit and Tobit findings, it is difficult to argue, it seems to us, that $N A C_{i}$ represent random and off-the-cuff answers by respondents trying to get the interviewer off their backs. This is especially so if one regards their yes-no answers as credible.

Tables 2 and 3 are more detailed analyses of the single-equation wife and husband models. Column 1 of each table has already been discussed. Columns 2 and 3 in each table represent an attempt to estimate specification (1.1) without husband-wife interaction, i.e. with $\mu_{i}=0$ and with the difference between the ideal and actual numbers of boys and girls as the primary explanatory variables. The conceptual problems with this specification have already been discussed, but we present these estimates for those of our readers who would nevertheless like to see what difference is made to the analysis by incorporating information which is typi cally not available in, say, the theory of the firm, i.e. information on desired stocks The results are not encouraging and the negative sign of the coefficients of $D G W$ and $D G H$ are puzzling. However, these can be explained through problems of multi. collinearity. It is clear, and preliminary runs not reported here bear it out further that $B$ and $G$ are instrumental variables for $B_{i}^{*}$ and $G_{i}^{*}$. Given this, our equations can be seen as suffering from a specification bias in that they use an independent variable along with its instrument and constrain their coefficients to be equal and opposite in sign. It is for this reason that we do not pursue specification (1.1) any further in terms of incorporating a simultaneous structure.

Columns 4 in Tables 2 and 3 represent a naive attempt to incorporate husband wife interaction. It is naive because all the estimates suffer from a simultaneous. equation bias. Nevertheless, the statistical significance and magnitude of the coefficient of $N A C H$ in the equation for $N A C W$ and vice versa bring out clearly the need for an analysis of a simultaneous-equation model.

We now turn to the principal results of this paper, i.e. those presented in Tables 4 and 5 and pertaining to the simultaneous-equation model. The specification of the model along with the expected signs is presented in Figure 1. Our specification is dictated not only by the underlying theory but also by previous work of the authors; see Khan and Sirageldin $[13 ; 14]$
Table 2

Demand for Additional Children in Pakistani Wives: Single Stage Tobit Estimates

\begin{tabular}{|c|c|c|c|c|}
\hline Independent Variables & Equation 1 & Equation 2 & Equation 3 & Equation 4 \\
\hline Intercept & $\begin{array}{r}3.646 \\
(4.66)\end{array}$ & $\begin{array}{r}3.405 \\
(4.21)\end{array}$ & $\begin{array}{c}3.370 \\
(4.08)\end{array}$ & $\begin{array}{l}2.860 \\
(3.52)\end{array}$ \\
\hline \multirow[t]{2}{*}{$A D H$} & -0.356 & -0.370 & -0.368 & -0.354 \\
\hline & $(1.83)$ & $(1.84)$ & $(1.83)$ & $(1.85)$ \\
\hline$A D W$ & $\begin{array}{r}-0.570 \\
(2.44)\end{array}$ & $\begin{array}{c}-0.708 \\
(3.09)\end{array}$ & -0.706 & -0.558 \\
\hline \multirow[t]{2}{*}{$A F$} & $\begin{array}{r}(2.44) \\
-0.088\end{array}$ & $\begin{array}{r}(3.09) \\
-0.215\end{array}$ & -0.214 & $\begin{array}{r}(2.41) \\
-0.078\end{array}$ \\
\hline & $(2.68)$ & (11.07) & (10.97) & $(3.23)$ \\
\hline$A$ & 0.112 & $\begin{array}{r}0.237 \\
(5.87)\end{array}$ & $\begin{array}{r}0.237 \\
(586)\end{array}$ & $\begin{array}{r}0.109 \\
(258)\end{array}$ \\
\hline \multirow[t]{2}{*}{$B$} & -1.000 & - & - & -0.913 \\
\hline & $(8.96)$ & & & $(8.09)$ \\
\hline$G$ & $\begin{array}{r}-0.484 \\
(4.41)\end{array}$ & - & - & -0.429 \\
\hline \multirow[t]{2}{*}{$E M$} & -0.004 & -0.005 & -0.004 & $\begin{array}{r}(3.91) \\
-0.004\end{array}$ \\
\hline & $(1.23)$ & $(1.39)$ & $(1.37)$ & $(1.21)$ \\
\hline \multirow[t]{2}{*}{$E F$} & -0.431 & -0.508 & -0.505 & -0.420 \\
\hline & $(0.93)$ & $(1.12)$ & $(1.11)$ & $(0.92)$ \\
\hline \multirow{2}{*}{$\begin{array}{l}L \\
N\end{array}$} & - & - & - & - \\
\hline & -0.273 & -0.522 & -0.520 & -0.242 \\
\hline & (1.16) & $(2.27)$ & $(2.26)$ & $(1.04)$ \\
\hline$U$ & -0.411 & $\begin{array}{r}-0.437 \\
(1.84)\end{array}$ & $\begin{array}{l}-0.439 \\
(1.84)\end{array}$ & -0.347 \\
\hline \multirow[t]{2}{*}{$\mathrm{NACH}$} & - & - & - & 0.198 \\
\hline & & & & $(3.07)$ \\
\hline$D B H$ & - & - & 0.017 & - \\
\hline \multirow{2}{*}{$D G H$} & - & & $\begin{array}{r}(0.22) \\
0.017\end{array}$ & - \\
\hline & & & $\begin{array}{r}0.017 \\
(0.13)\end{array}$ & \\
\hline \multirow[t]{2}{*}{$D B W$} & - & 0.474 & 0.468 & - \\
\hline & & $(5.90)$ & $(5.56)$ & \\
\hline \multirow[t]{2}{*}{$D G W$} & - & -0.758 & -0.755 & - \\
\hline & & $(9.17)$ & $(8.91)$ & \\
\hline \multirow{3}{*}{$\begin{array}{l}\text { Standard Error of Reg. } \\
\text { Lost Degrees of Freedom } \\
\text { Log of }{ }^{2} \text { Likelihood }\end{array}$} & 2.641 & 2.633 & 2.633 & 2.615 \\
\hline & 10 & 10 & 12 & 11 \\
\hline & -1128 & -1131 & -1131 & -1123 \\
\hline \multirow{3}{*}{$\begin{array}{l}\text { Number of Observations } \\
\text { Mean and Standard Dev. } \\
\text { of Dep. Var. } \\
\text { Number of Limit Obs. }\end{array}$} & & & & 804 \\
\hline & & & & $\begin{array}{c}1.387 \\
(1.834)\end{array}$ \\
\hline & & & & 427 \\
\hline
\end{tabular}




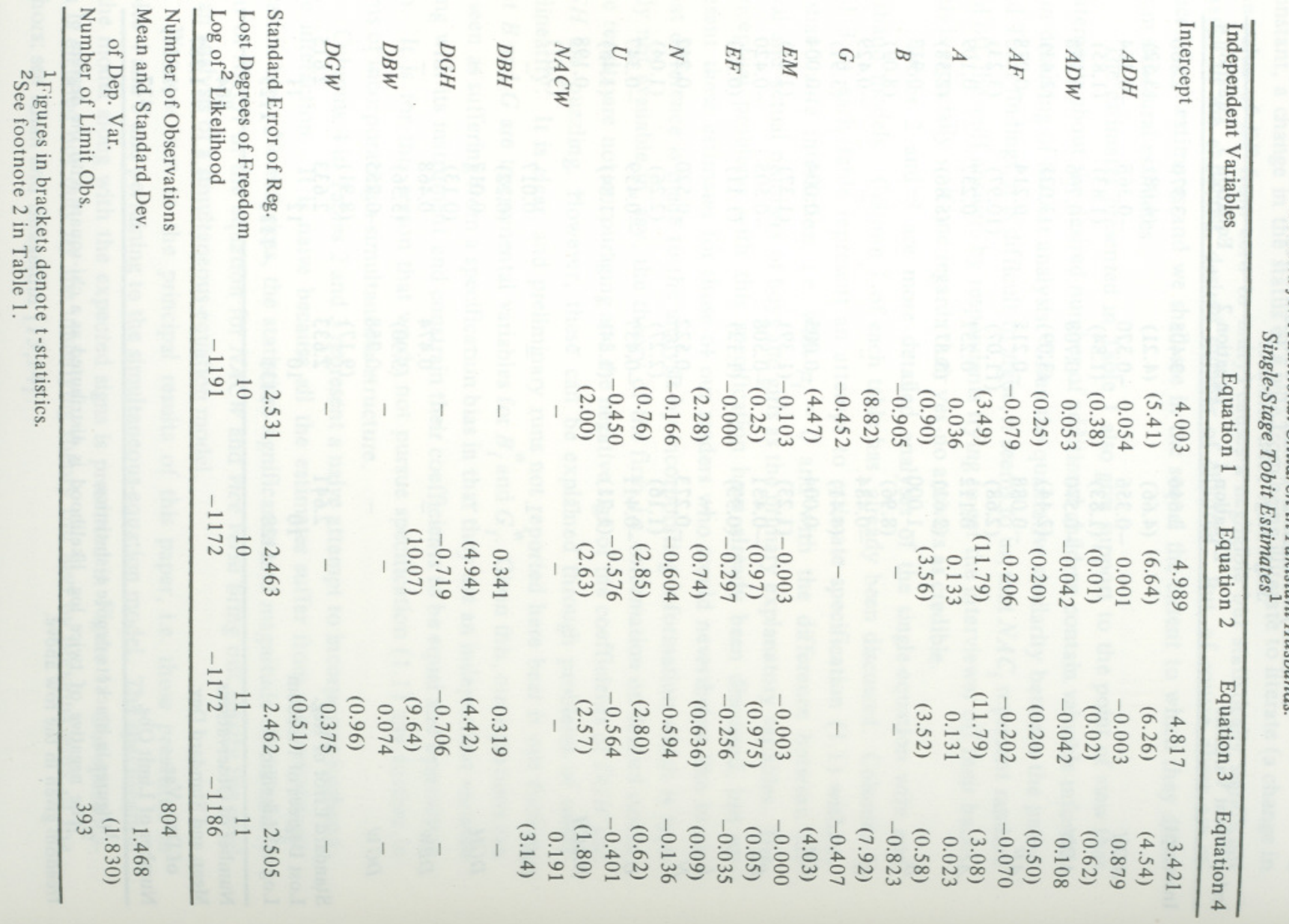

Table 4

Demand for Additional Children in Pakistani Wives: Simultaneous-Equation Estimates ${ }^{1,2}$

\begin{tabular}{|c|c|c|c|c|c|c|c|c|}
\hline \multirow{2}{*}{ Independent Variables } & \multicolumn{2}{|c|}{$\begin{array}{c}\text { Two Stage Least } \\
\text { Squares Estimates }\end{array}$} & \multicolumn{3}{|c|}{ Heckman Two-Stage Estimates ${ }^{4}$} & \multicolumn{3}{|c|}{$\begin{array}{c}\text { The Two-Stage Tobit Esti- } \\
\text { mates }\end{array}$} \\
\hline & $O L S^{3}$ & $2 S L S$ & $O L S^{3}$ & $2 S L S$ & $2 S L S$ & $S S T^{3}$ & $2 S T$ & $\begin{array}{l}\text { Partial Derivatives } \\
\text { at Point of Means }\end{array}$ \\
\hline Intercept & 3.155 & -19.778 & 5.171 & 0.566 & 0.386 & $\begin{array}{r}3.747 \\
(4.83)\end{array}$ & $\begin{array}{c}3.120 \\
(3.60)\end{array}$ & 1.454 \\
\hline$A D H$ & $\begin{array}{c}-0.169 \\
(2.11)\end{array}$ & $\begin{array}{c}-0.093 \\
(0.89)\end{array}$ & $\begin{array}{l}0.146 \\
(0.51)\end{array}$ & $\begin{array}{c}-0.126 \\
(0.65)\end{array}$ & $\begin{array}{c}-0.101 \\
(0.71)\end{array}$ & $\begin{array}{c}-0.341 \\
(1.77)\end{array}$ & $\begin{array}{c}-0.380 \\
(1.94)\end{array}$ & -0.177 \\
\hline$A D W$ & $\begin{array}{c}-0.268 \\
(2.29)\end{array}$ & $\begin{array}{c}-0.333 \\
(2.73)\end{array}$ & $\begin{array}{l}0.294 \\
(0.76)\end{array}$ & $\begin{array}{c}-0.229 \\
(0.76)\end{array}$ & $\begin{array}{c}-0.190 \\
(0.89)\end{array}$ & $\begin{array}{c}-0.570 \\
(2.44)\end{array}$ & $\begin{array}{c}-0.604 \\
(2.58)\end{array}$ & -0.282 \\
\hline$A F$ & $\begin{array}{r}-0.057 \\
(4.61)\end{array}$ & $\begin{array}{r}0.305 \\
(1.01)\end{array}$ & $\begin{array}{c}-0.114 \\
(3.33)\end{array}$ & $\begin{array}{r}-0.009 \\
(0.22)\end{array}$ & $\begin{array}{r}-0.003 \\
(0.12)\end{array}$ & $\begin{array}{c}-0.900 \\
(3.75)\end{array}$ & $\begin{array}{c}-0.102 \\
(4.00)\end{array}$ & -0.048 \\
\hline$A$ & $\begin{array}{r}0.061 \\
(2.73)\end{array}$ & $\begin{array}{c}-0.043 \\
(0.50)\end{array}$ & $\begin{array}{c}-0.009 \\
(1.18)\end{array}$ & $\begin{array}{r}0.065 \\
(1.50)\end{array}$ & $\begin{array}{r}0.061 \\
(2.65)\end{array}$ & $\begin{array}{c}0.104 \\
(2.46)\end{array}$ & $\begin{array}{r}0.997 \\
(2.36)\end{array}$ & -0.046 \\
\hline$B$ & $\begin{array}{c}-0.340 \\
(7.06)\end{array}$ & $\begin{array}{c}1.692 \\
(1.00)\end{array}$ & $\begin{array}{r}-1.307 \\
(3.22)\end{array}$ & $\begin{array}{c}-0.240 \\
(0.55)\end{array}$ & $\begin{array}{r}-0.175 \\
(0.67)\end{array}$ & $\begin{array}{c}-1.024 \\
(9.23)\end{array}$ & $\begin{array}{c}-1.049 \\
(9.13)\end{array}$ & -0.489 \\
\hline G & $\begin{array}{c}-0.188 \\
(3.81)\end{array}$ & $\begin{array}{r}1.081 \\
(1.02)\end{array}$ & $\begin{array}{c}-0.904 \\
(4.51)\end{array}$ & $\begin{array}{c}-0.053 \\
(0.20)\end{array}$ & $\begin{array}{c}-0.014 \\
(0.09)\end{array}$ & $\begin{array}{c}-0.501 \\
(4.59)\end{array}$ & $\begin{array}{c}-0.520 \\
(4.63)\end{array}$ & -0.242 \\
\hline$E M$ & $\begin{array}{c}-0.002 \\
(1.19)\end{array}$ & - & $\begin{array}{c}0.001 \\
(0.27)\end{array}$ & - & - & $\begin{array}{r}-0.005 \\
(1.62)\end{array}$ & - & - \\
\hline$m_{W}$ & - & - & $\begin{array}{c}-4.029 \\
(1.42)\end{array}$ & $\begin{array}{c}-0.580 \\
(0.35)\end{array}$ & $\begin{array}{r}-0.825 \\
(0.84)\end{array}$ & - & - & - \\
\hline$m_{H}$ & - & - & $\begin{array}{r}9.447 \\
(2.88)\end{array}$ & - & - & - & - & - \\
\hline$U$ & $\begin{array}{c}-0.279 \\
(2.34)\end{array}$ & $\begin{array}{l}1.424 \\
(0.97)\end{array}$ & $\begin{array}{c}-0.798 \\
(3.44)\end{array}$ & $\begin{array}{c}-0.061 \\
(0.19)\end{array}$ & - & $\begin{array}{c}-0.454 \\
(1.93)\end{array}$ & $\begin{array}{c}-0.612 \\
(2.67)\end{array}$ & -0.285 \\
\hline
\end{tabular}




\begin{tabular}{|c|c|c|c|c|c|c|c|c|}
\hline \multirow{2}{*}{ Independent Variables } & \multicolumn{2}{|c|}{$\begin{array}{l}\text { Two Stage Least } \\
\text { Squares Estimates }\end{array}$} & \multicolumn{4}{|c|}{ Heckman Two-Stage Estimates ${ }^{4}$} & \multicolumn{2}{|c|}{$\begin{array}{c}\text { The Two-Stage Tobit Esti- } \\
\text { mates }\end{array}$} \\
\hline & $O L S^{3}$ & $2 S L S$ & $O L S^{3}$ & $2 S L S$ & $2 S L S$ & $S S T^{3}$ & $2 S T$ & $\begin{array}{l}\text { Partial Derivatives } \\
\text { at Point of Means }\end{array}$ \\
\hline $\mathrm{NACH}$ & - & $\begin{array}{l}6.203 \\
(1.20)\end{array}$ & - & $\begin{array}{r}0.496 \\
(1.68)\end{array}$ & $\begin{array}{r}0.534 \\
(2.51)\end{array}$ & - & $\begin{array}{r}3.289 \\
(1.83)\end{array}$ & 1.532 \\
\hline F-Value & 37.612 & 27.614 & 10.32 & 10.42 & 11.75 & & & \\
\hline$R^{2}$ & 0.52 & 0.52 & 0.45 & 0.42 & 0.42 & & & \\
\hline Standard Error of Regression ${ }^{5}$ & 1.58 & 1.58 & 1.440 & 1.746 & 1.742 & 2.648 & 2.664 & \\
\hline Lost degrees of Freedom & 8 & 8 & 10 & 9 & 8 & 8 & 8 & \\
\hline Number of Observations & 804 & 804 & 377 & 377 & 377 & 804 & 804 & \\
\hline $\begin{array}{l}\text { Mean and Standard Dev. of } \\
\text { Dep. Var. }\end{array}$ & $\begin{array}{c}1.387 \\
(1.834)\end{array}$ & $\begin{array}{c}1.387 \\
(1.834)\end{array}$ & $\begin{array}{c}2.958 \\
(1.589)\end{array}$ & $\begin{array}{c}2.958 \\
(1.589)\end{array}$ & $\begin{array}{c}2.958 \\
(1.589)\end{array}$ & $\begin{array}{c}1.387 \\
(1.834)\end{array}$ & $\begin{array}{c}1.387 \\
(1.834)\end{array}$ & \\
\hline Log of Likelihood & & & & & & 1129 & -1129 & \\
\hline Number of Limit Observations & & & & & & 427 & 427 & \\
\hline
\end{tabular}

Number of Limit Observations

${ }^{1}$ Figures in brackets denote $t$-statistics in all columns.

${ }^{2} O L S$ stands for ordinary least squares; $2 S L S$ for 2 -stage least squares; $S S T$ for single-stage Tobits; and $2 S T$ for two-stage Tobits.

${ }^{3}$ These are all reduced from estimates to get predicted values of the endogenous variables.

${ }^{4}$ Recall that $m_{H}$ and $m_{W}$ are estimated from probit analysis. The estimates of these underlying equations are not reported here. Such equations utilized all variables except $N A C H$ as explanatory variables.

${ }^{5}$ Both the estimate of the standard error and the $R^{2}$ are adjusted for degrees of freedom.

Table 5

Demand for Additional Children in Pakistani Husbands: Simultaneous Equation Estimates ${ }^{1,2}$

\begin{tabular}{|c|c|c|c|c|c|c|c|}
\hline \multirow[b]{2}{*}{ Independent Variables } & \multicolumn{2}{|c|}{$\begin{array}{c}\text { Two Stage Least Squares } \\
\text { Estimates }\end{array}$} & \multicolumn{2}{|c|}{$\begin{array}{c}\text { Heckman Two-Stage } \\
\text { Estimates }\end{array}$} & \multicolumn{3}{|c|}{ The Two-Stage Tobit Estimates } \\
\hline & $O L S^{3}$ & $2 S L S$ & $O L S^{3}$ & $2 S L S$ & $S S T^{3}$ & $2 S T$ & $\begin{array}{l}\text { Partial Derivatives } \\
\text { at Point of Means }\end{array}$ \\
\hline Intercept & 3.70 & 3.511 & 4.785 & 4.818 & $\begin{array}{r}4.019 \\
(5.48)\end{array}$ & $\begin{array}{r}4.680 \\
(7.59)\end{array}$ & 2.511 \\
\hline$A D H$ & $\begin{array}{c}-0.012 \\
(0.15)\end{array}$ & - & $\begin{array}{c}-0.418 \\
(1.59)\end{array}$ & - & $\begin{array}{r}0.055 \\
(0.38)\end{array}$ & - & - \\
\hline$A D W$ & $\begin{array}{r}0.011 \\
(0.09)\end{array}$ & - & $\begin{array}{c}-0.582 \\
(1.64)\end{array}$ & - & $\begin{array}{l}0.056 \\
(0.26)\end{array}$ & - & - \\
\hline$A F$ & $\begin{array}{c}-0.058 \\
(4.74)\end{array}$ & $\begin{array}{r}-0.051 \\
(3.11)\end{array}$ & $\begin{array}{r}-0.155 \\
(5.25)\end{array}$ & $\begin{array}{c}-0.094 \\
(1.68)\end{array}$ & $\begin{array}{c}-0.080 \\
(3.55)\end{array}$ & $\begin{array}{r}-0.073 \\
(3.35)\end{array}$ & -0.039 \\
\hline$A$ & $\begin{array}{r}0.017 \\
(0.74)\end{array}$ & - & $\begin{array}{r}0.095 \\
(2.06)\end{array}$ & - & $\begin{array}{r}0.035 \\
(0.37)\end{array}$ & - & - \\
\hline$B$ & $\begin{array}{r}-0.328 \\
(6.75)\end{array}$ & $\begin{array}{c}-0.294 \\
(2.91)\end{array}$ & $\begin{array}{r}-1.661 \\
(5.11)\end{array}$ & $\begin{array}{r}-1.226 \\
(1.73)\end{array}$ & $\begin{array}{r}-0.917 \\
(8.99)\end{array}$ & $\begin{array}{c}-0.942 \\
(9.39)\end{array}$ & -0.504 \\
\hline$G$ & $\begin{array}{r}-0.205 \\
(4.14)\end{array}$ & $\begin{array}{c}-0.189 \\
(2.63)\end{array}$ & $\begin{array}{c}-1.043 \\
(6.18)\end{array}$ & $\begin{array}{c}-0.738 \\
(1.65)\end{array}$ & $\begin{array}{r}-0.463 \\
(4.62)\end{array}$ & $\begin{array}{r}-0.485 \\
(5.03)\end{array}$ & -0.260 \\
\hline$E M$ & $\begin{array}{c}-0.000 \\
(0.19)\end{array}$ & $\begin{array}{r}0.000 \\
(0.09)\end{array}$ & $\begin{array}{r}-0.007 \\
(2.47)\end{array}$ & $\begin{array}{c}-0.000 \\
(0.05)\end{array}$ & $\begin{array}{c}-0.000 \\
(0.09)\end{array}$ & $\begin{array}{r}0.001 \\
(0.19)\end{array}$ & 0.000 \\
\hline$m_{W}$ & - & - & 4.425 & - & - & - & - \\
\hline$U$ & $\begin{array}{c}-0.274 \\
(2.29)\end{array}$ & $\begin{array}{c}-0.248 \\
(1.93)\end{array}$ & $\begin{array}{c}-0.935 \\
(4.40)\end{array}$ & $\begin{array}{c}-0.738 \\
(1.88)\end{array}$ & $\begin{array}{r}-0.457 \\
(2.08)\end{array}$ & $\begin{array}{r}-0.459 \\
(2.12) \\
\end{array}$ & -0.246 \\
\hline
\end{tabular}


Independent Variables

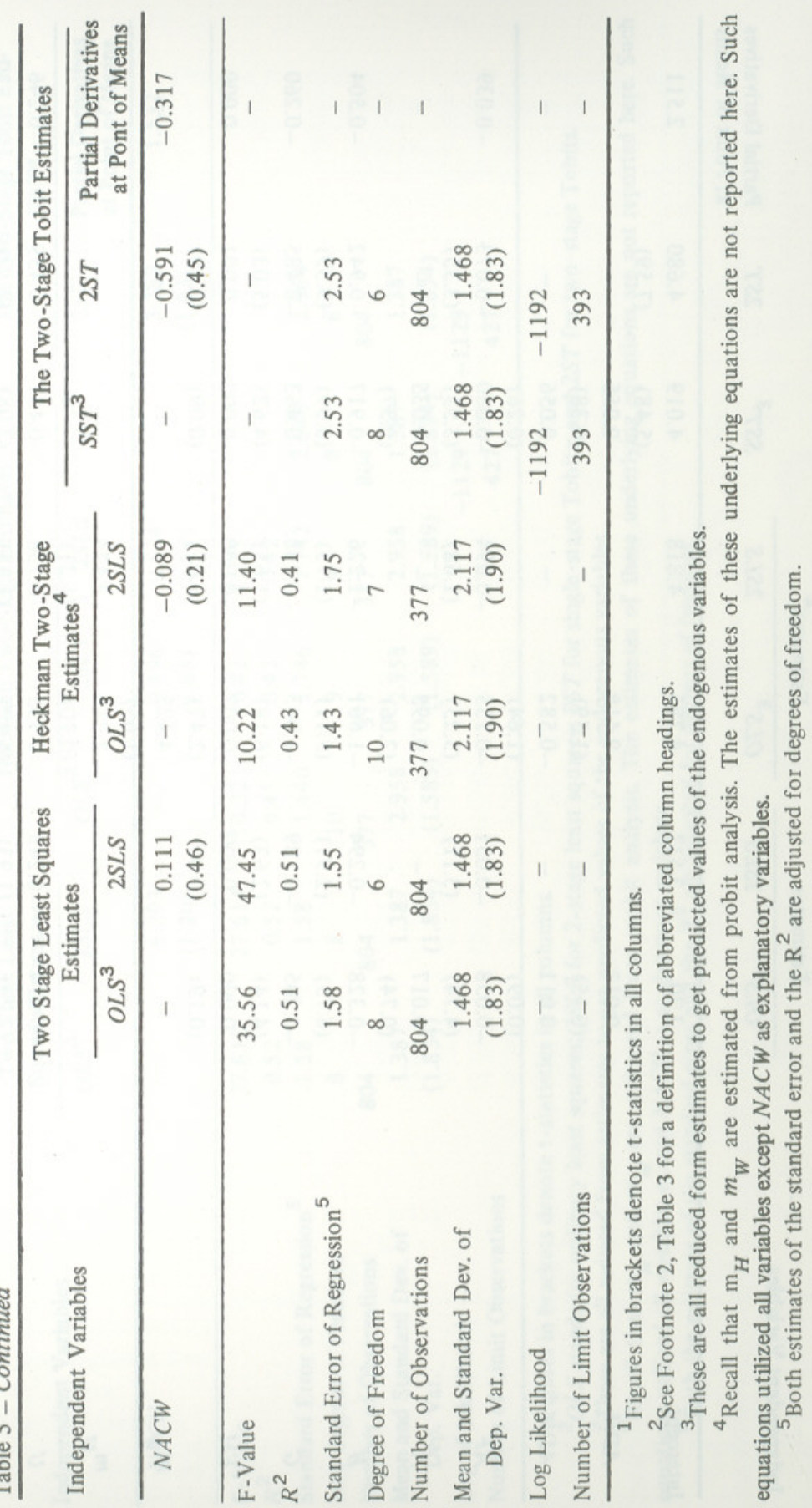

\begin{tabular}{|c|c|c|c|c|c|c|c|c|c|c|c|}
\hline \multirow{4}{*}{$\begin{array}{l}\text { Dependent } \\
\text { Variables }\end{array}$} & & \multicolumn{4}{|c|}{ Endogenous } & \multicolumn{6}{|c|}{ Exogenous } \\
\hline & & $N A C W$ & $\mathrm{NACH}$ & $A D W$ & $A D H$ & $B$ & $G$ & $A F$ & A & $E M$ & $U$ \\
\hline & $N A C W$ & & + & + & + & - & - & - & + & & - \\
\hline & $N A C H$ & + & & & & - & - & - & & - & - \\
\hline
\end{tabular}

Figure 1: The Simultaneous-Equation Model

The two-stage Tobit estimates along with the partial derivatives evaluated at The last two columns of each of Tables 4 and 5. Given these estimates, we can ask the following questions:

(a) Have we gained anything from using these sophisticated techniques in preference to the method of two-stage least squares?

(b) How much difference is there between structural and reduced-form estimates?

(c) How do the Tobit estimates compare with the probit estimates of the simultaneous-equation model, i.e. do we gain anything from incorporating the additional information of $N A C_{i}$ ?

(d) How do the Tobit two-stage estimates compare with the Heckman two stage estimates?

We leave it to the interested reader to answer questions (a), (b) and (d) for himself. We only point out that it is an affirmative answer to question (c) that makes our analysis worthwhile. In our previous work on the probit model [13], we concluded

"that not one variable other than the husband's demand for additiona children is a significant factor in explaining the wife's demand. Indeed, the highest t-statistic among the remaining determinants is 0.53 . The situation is somewhat better on the husband's side. In addition to wife's demand, the age of wife, the number of boys, and, to a lesser extent, the number of girls are significant determinants of husband's demands."

It is clear that these conclusions have to be drastically revised on the wife's side. There is husband-wife interaction but it is far from being so strongly recursive as we supposed from our probit estimates. A more detailed comparison is left to the reader.

\section{CONCLUDING REMARKS}

In summary, we can draw the following conclusions relating to husband-wife interaction and son preference: 
1. A one-unit increase in the number of children desired by the husband causes, ceteris paribus, an increase of 1.5 in the expected number of children desired by the wife. This coefficient has a t-statistic of 1.83 .

2. The number of children desired by the wife has no effect on the number of those desired by the husband.

3. The greater the number of living sons or living daughters, the smaller the expected number of children desired by the husband and the wife, every. thing else remaining constant.

4. The negative inducement due to the number of living sons on the desired number of additional children is about two times that due to the number of living daughters. This is as true for wives' responses as for their husbands'.

\section{REFERENCES}

1. Amemiya, T. "The Estimation of a Simultaneous-Equation Tobit Model". International Economic Review. Vol. 20. 1979. pp. 169-81.

2. Amemiya, T. "Multivariate Regression and Simultaneous Equation Models when the Dependent Variables are Truncated Normal". Econometrica. Vol. 42. 1974. pp. 999-1012.

3. Amemiya, T. "Regression Analysis when the Dependent Variable is Truncated Normal”. Econometrica. Vol. 41. 1973. pp. 997-1016.

4. Blake, J. "Can We Believe Recent Data on Birth Expectations in the United States?” Demography. Vol. 11. 1974. pp. 25-44.

5. Bumpass, L. L. “Comment on Judith Blake's 'Can We Believe Recent Data on Birth Expectations in the United States?' " Demography. Vol. 12. 1975. pp. 155-56.

6. Coombs, L. C. "The Measurement of Family Size Preferences and Subsequent Fertility”. Demography. Vol. 11. 1974. pp. 587-611.

7. Freedman, R., A. I. Hermalin and Mung-Chang. "Do Statements About Desired Family Size Predict Fertility? The Case of Taiwan 1967-1970”. Demography. Vol. 12. 1975. pp. 407-16.

8. Heckman, J. J. "The Common Structure of Statistical Models of Truncation; Sample Selection and Limited Dependent Variables and a Simple Estimator for such Models". Annals of Economic and Social Measurement. Vol. 5, No. 4. 1976. pp. 475-92.

9. Heckman, J. J. "Sample Bias as a Specification Error". Econometrica. Vol. 47. 1979. pp. 153-62.

10. Hermalin, A., R. Freedman, T. H. Sun and M-C. Chang. "Do Intentions Predict Fertility? The Experience in Taiwan, 1967-74". Studies in Family Planning. Vol. 10, No. 3. 1979. pp. 75-95.
11. Keeley, M. S. "An Interpretation of the Economic Theory of Fertility". Journal of Economic Literature. Vol. XII. 1975. pp. 481-96.

12. Khan, M. Ali. "Relevance of Human Capital Theory to Fertility Research: Comparative Findings for Bangladesh and Pakistan". Research in Human Capital and Development. Vol. 1. 1979. pp. 1-42.

13. Khan, M. Ali, and I. Sirageldin. "Intrafamily Interaction and Desired Additional Fertility in Pakistan: A Simultaneous-Equation Model with Dichotomous Dependent Variables". Pakistan Development Review. Vol. XX, No. 1. Spring 1981.

14. Khan, M. Ali, and I. Sirageldin. "Son Preference and the Demand for Additional Children in Pakistan”. Demography. Vol. 14. 1977. pp. 481-95. Reprinted in B. Boulier (ed.), Household Models of Economic Demographic Decision Making. Liege, Belgium: IUSSP Press.

15. Kruegel, D. L. "Further Comment on J. Blake's 'Can We Believe Recent Data on Birth Expectations in the United States?' " Demography. Vol. 12. 1975. pp. $157-61$.

16. Lee, L. "Estimation of Limited Dependent Variable Models by Two-Stage Methods”. Unpublished Doctoral Dissertation, University of Rochester. 1976.

17. Lee, L., G. S. Maddala and R. P. Trost. "Asymptotic Covariance Matrices of TwoStage Probit and Two-Stage Tobit Methods for Simultaneous Equations Models with Selectivity". Econometrica. Vol. 48. 1980. pp. 491-504.

18. Leibenstein, H. "On the Economic Theory of Fertility: A Reply to Keeley" Journal of Economic Literature. Vol. XIII. 1975. pp. 469-71.

19. Maddala, G. S. Econometrics. New York: McGraw-Hill Book Company. 1977.

20. Maddala, G. S. "Selectivity Problems in Longitudinal Data". In The Econometrics of Panel Data. Annales de 1'insee 30-31. April-September 1978. pp. 423-50.

21. Maddala, G. S. "Self-Selectivity Problems in Econometric Models". In P. R. Krishniah (ed.), Applications of Statistics. Amsterdam: North Holland Publishing Company. 1976.

22. McFadden, D. "Comments on 'Estimation of a Stochastic Model of Reproduction: An Econometric Approach" ". In N.E. Terleckyj (ed.), Household Production and Consumption. New York: Columbia University Press. 1975.

23. Mortenson, D. T. "Generalized Costs of Adjustment and Dynamic Factor Demand Theory”. Econometrica. Vol. 41. 1973. pp. 657-65.

24. Namboodiri, N. K. "A Reply to Rosenzweig and Seiver". Demography. Vol. 12. 1975. pp. 669-70.

25. Namboodiri, N. K. "Some Observations on the Economic Framework for Fertility Analysis”. Population Studies. Vol. 26. 1972. pp. 185-206.

26. Namboodiri, N. K. "Which Couples at Given Parities Expect to have Additional Births? An Exercise in Discriminant Analysis". Demography. Vol. 11, No. 1. 1974. pp. $45-56$. 
27. Nelson, F., and L. Olson. "Specification and Estimation of a Simultaneous Equation Model with Limited Dependent Variables". International Economic Review. Vol. 19. 1968. pp. 695-709.

28. Pakistan Family Planning Council. Survey Design and Development: National Impact Survey. Lahore: Training, Research and Evaluation Centre (TREC). 1969.

29. Rosenzweig, M. R., and D. A. Seiver. “Comment on N. K. Namboodiri's 'Which Couples at Given Parities Expect to have Additional Birth? An Exercise in Discriminant Analysis" ". Demography. Vol. 12, No. 4. 1975. pp. 665-668.

30. Schultz, T. W. (ed.). Economics of the Family: Marriage, Children and Human Capital. Chicago: University of Chicago Press. 1974.

31. Shah, N. M. "Interspousal Communication and Agreement at Variables in the Study of Family Planning". Unpublished Ph. D. Dissertation, The Johns Hopkins University, Baltimore, Maryland. 1974.

32. Sirageldin, I. "The Survey Method in Family Planning Research and Evaluation". In J. F. Kantner and Lee McCaffrey (eds.), Population and Development in Southeast Asia. Lexington, Mass.: Lexington Books. 1975.

33. Sirageldin, I., and G. Hardee. "A Flexible Interaction Model for Analyzing Sample Survey Data for Planning and Evaluation of Fertility Control in Pakistan". CENTO Symposium on Demographic Statistics, Karachi (1968), published August 1970 by Office of United States Economic Coordinator for CENTO Affairs.

34. Tobin, J. "The Application of Multivariate Probit Analysis to Economic Survey Data". Cowles Foundation Discussion Paper No. 1. New Haven: Yale University. 1955.

35. Westoff, C. F., and N. B. Ryder. "The Predictive Validity of Reproductive Intentions". Demography. Vol. 14. 1977. pp. 431-54. 